Check for updates

1 Doctors' Association UK

2 The On-Call Room

3 South West London

Cite this as: $B M / 2022 ; 376: 0162$ http://dx.doi.org/10.1136/bmj.o162 Published: 20 January 2022

\title{
What implications does the Toombes vs Mitchell case have for other healthcare professionals?
}

\author{
Ellen Welch, ${ }^{1}$ Jenny Vaughan, ${ }^{1}$ Kristina Rebecca Cranfield, ${ }^{2}$ Roshana Mehdian ${ }^{3}$
}

The recent case of Toombes vs Mitchell made legal history and the medical profession have been considering the potential implications ever since. ${ }^{1-3}$ Evie Toombes, a para-showjumper and disability activist, who was born with a neural tube defect, successfully sued her mother's general practitioner, Philip Mitchell, arguing that she would never have been conceived had her mother been given adequate pre conceptual advice.

The case centred on the advice given by Mitchell around the role of folic acid supplements before and during pregnancy. His notes of "Folate if desired" written over 20 years earlier, and of which he had no recollection, were deemed "completely inadequate" by the judge. ${ }^{1-3}$ Instead, the evidence of Evie Toombes' mother, Caroline Toombes, was accepted. She recalls being told folic acid supplementation was unnecessary if she had a good diet. The Judge Rosalind Coe QC, concluded that, had Mitchell advised Caroline Toombes differently, then she would have delayed conception, resulting in a genetically different child. A court agreed last year that later conception would on the balance of probabilities have resulted in the birth of a healthy baby.

Legal opinion currently is that although this case should not open the floodgates to further cases, it has altered the legal landscape in that a child can bring a claim for disabilities arising from possible negligence before they were born.

The question raised for other clinicians over this ruling is whether this is a unique case or whether it has broader implications for all NHS workers. Mitchell relied on what would have been his standard practice, and his notes, which although brief, (this was 20 years ago) did mention a discussion about folic acid. This was not consent for an operation and it was not recognised practice at the time that routine GP consultations should document patient questions or ensure that their understanding was checked and documented. At the time, this would have been seen as a somewhat "low risk" consultation, yet the amount of documentation expected by the judge was, in the opinion of many, in excess of what would have been standard practice by most doctors at the time.

We need to take time to fully understand why the judge came to the conclusions she did, and to consider as a medical profession what this means for clinical practice. We hope that the ruling will not have a negative impact on the complex trust relationship that exists within every consultation and which is essential for a caring and compassionate health service. However, we also recognise that young people born with a disability have many challenges to overcome. Healthcare professionals are already under immense pressure to see more patients in less time and many healthcare professionals are calling for audio or video consultation recording as a matter of course. There are huge concerns about the increasing practice of defensive medicine, instead of appropriate medicine, as well as the cost of soaring insurance fees.

We need to discuss as a profession how we can enable clinicians to feel they are safe doing their job. Perhaps it is time to consider a no-fault medical regulatory system such as the current set up in New Zealand, where patients can ensure they are assisted with the costs of injury, but are unable to sue for damages. ${ }^{4}$ This saves time and money and removes the huge burden on doctors to practice defensively.

Our concerns are that a much more defensive type of medicine may result and consultations could take longer thus reducing access for patients. This is to the detriment of patient care. Any possible implications for our working environment should be studied. We believe that this case has highlighted that it could be any one of us in this position.

Competing interests: none declared

Provenance and peer review: commissioned, not peer reviewed

Acknowledgments: Samantha Batt-Rawden, ST7 Intensive Care Medicine and Pre-Hospital Medicine, NHS Million, John Hughes, chair GP Survival, Mark Green, GP The On-Call Room

1 Papanikitas A, Spicer J, Hayhoe B. "Wrongful conception” ruling against UK general practitioner. BMJ2022;376:079 doi: 10.1136/bmj.o79. pmid: 35031556

2 Dyer C. Showjumper sues mother's GP for inadequate advice that led to her spina bifida. BMJ 2021;375:n2919. doi: 10.1136/bmj.n2919. pmid: 34836877

3 Dyer C. Show jumper wins case against mother's GP for "wrongful conception" that resulted in her disability. BMJ2021;375:n2999. doi: 10.1136/bmj.n2999. pmid: 34862168

4 Wallis KA. No-fault, no difference: no-fault compensation for medical injury and healthcare ethics and practice. Br J Gen Pract 2017;67:38-9. doi: 10.3399/bjgp17X688777. pmid: 28034949 